\title{
University students' attitude to distance learning in situation of uncertainty
}

\author{
Irina Abakumova ${ }^{1}$, Galina Zvezdina ${ }^{1}$, Anastasia Grishina ${ }^{1, *}$, Ekaterina Zvezdina ${ }^{1}$, and \\ Elena Dyakova ${ }^{2}$ \\ ${ }^{1}$ Don State Technical University, Gagarin sq., 1, Rostov on Don, 344003, Russia \\ ${ }^{2}$ Rostov State Transport University, Rostov Rifle Regiment of the People's Militia Sq., 2, Rostov-on- \\ Don, 344038, Russia
}

\begin{abstract}
The article presents an analysis of using distance learning technology in university education in the context of the COVID-19 pandemic and the attitude of students to this format of education. The authors justify the urgency of the problem under study for modern education and update the basic requirements for education in the situation of growing uncertainty. The paper describe the methodological foundations and genesis of the development of distance learning, distinguishes the concepts of "distance education" and "distance learning". The authors determine the features of distance learning in modern conditions and highlight the main problems and contradictions that were provoked by the COVID-19 pandemic and the social isolation. The aim of this study is to evaluate emotional attitude of university students of the humanities and natural sciences to distance learning, implemented in the pandemic situation. The presented results of an empirical study reveal the pros and cons of distance learning, the active use of Internet resources by students in learning, and the willingness to rebuild in a changing environment.
\end{abstract}

\section{Introduction}

The rapidly changing socio-cultural situation with a high level of uncertainty requires changes in the educational system in higher education. The focus on mobility, flexibility, the ability to redefine and take into account the demands of modern life trigger innovative processes in education.

The main innovations in education relate to the goal of education and changes in the position of the educational process subjects. Modern school must teach a person to learn. Leading researchers in educational psychology agree that in the world of uncertainty, complexity and diversity, the key competence of a person is the ability to renew their competencies.

Uncertainty is becoming a constant companion of modern life. According to the dictionary definition, uncertainty is considered as a state, when a person is not fully convinced. In information theory uncertainty is understood as the degree to which no

\footnotetext{
*Corresponding author: avgrishina.donstu@gmail.com
} 
restrictions are imposed on the possible choices available, or on the possible consequences of the situation.

Uncertainty can be regarded as "the conditions of a person's life, influencing the course of his activity, expressed in the absence or presence of the subject of semantic reference points of his inner life. The human attitude to uncertainty appears in accepting these conditions or rejecting them "[1].

The current social situation with the coronavirus pandemic has posed complex and ambiguous tasks for society and its social institutions. In order to preserve the health of children and youth, education faced the problem of organizing distance education for them.

Though distance learning is not a new topic, but in current situation it requires a new look at the organization of distance learning and the use of new methods and approaches to learning. Distance learning has a fairly long history of application in education. Distance learning has its origins in the 18th century, which was organized first using the postal service, and later radio. With the advent of television in the middle of the 20th century, it becomes more widespread. However, distance technologies were systematically used, mainly in specialized educational institutions (Open University, Coastline Community College), or in specialized courses $[2,3,4]$.

With the invention of the computer and the Internet, distance learning has become widespread in educational institutions of various types. However, distance technologies in mass education were applied fragmentarily and were mostly used in part-time forms of education.

The beginning of the 21 st century marked a new stage in the development of distance learning. The active use of information and communication technologies (ICT) allowed the teacher and the student to interact in real time on the subject. This allowed the wider use of distance learning, including different levels of education from preschool higher and additional.

The use of distance learning in the context of the COVID-19 coronavirus pandemic turned out to be ubiquitous and uncontested, which led to the need to revise the organization of training and teaching methods. Higher education has responded to the challenges of modern times, however, in such conditions, many contradictions and problems, that require the resolution, have appeared. Firstly, the educational environment of the university was technically not ready for such volume of online connections, which manifested itself in failures, disconnections, and equipment mismatch with the applied loads. Secondly, the technical and methodological unwillingness of teachers to carry out the educational process in a distance format using ICT. Thirdly, the psychological unwillingness of teachers and students to interact online constantly and to accept this teaching format. Fourth, the lack of an opportunity to choose the form of education, the need to be constantly in the informational space, which provoked an increase in tension and resistance, both among teachers and students. [5,6,7,8,9]

At the same time, as the researchers note, along with the obvious challenges and problems, the new teaching format provides a wide range of opportunities and prospects for changing and improving educational systems, for which a critical situation creates forced conditions.

The effectiveness of education is largely determined by the attitude of students to the format, to the methods and techniques that are used in education and, finally, the psychological readiness of the students themselves to perceive information remotely. In this regard, it becomes of current interest to study the emotional and evaluative attitude of university students to the distance learning format and the ability to rebuild and accept new challenges of the time.

\section{Research methodology and methods}


In pedagogy, it is customary to differentiate the concepts of "distance education" and "distance learning". To understand this issue, we will conduct a comparative analysis of these concepts.

Distance education is a form of education that differs from other forms in the way of obtaining (providing) education or the nature of educational communication, carried out mainly indirectly at a distance [10].

Distance learning is the interaction of a teacher and students with each other at a distance, realized by all components inherent in the educational process (goals, content, methods, organizational forms, teaching aids), specific means of Internet technologies or others that provide for interactivity $[10,11]$.

It is the distance form of education that scientists consider the main form of education in the information society (E.S. Polat, A.A. Andreev, V. I. Soldatkin, S. A. Shchennikov, A. $\mathrm{V}$. Khutorskoy). The authors agree that distance learning technologies are only a part of the distance learning system, an important component of this system, but not the system itself. Distance learning technologies allow you to optimize the educational process, make it more dynamic, holistic, flexible. This is especially clearly manifested in this type of activity as the independent work of students, which is present in all forms of education [10,11,12].

Distance learning is a new form of education, which is based on a new scientific theory, different from traditional didactics. Scientists are convinced that distance learning obeys the laws of its didactic structure, and also has great pedagogical potential [12,13].

Distance learning using Internet technologies allows the teacher to focus on the needs of the student, implementing an individual approach and stimulating the independence and activity of students.

According to the researchers, new information technologies, mobile devices allow participants in the learning process to interact at a distance without leaving their home or office, providing interactive communication between them, which has always been an indisputable advantage in the face-to-face training system [12,13].

In the context of the actualization of individualized training of students, the role of distance education is increasing. The new opportunities are opening up for the implementation of an individual educational route, increasing the creative and intellectual potential of students.

The modern psychological and pedagogical literature reflects the description of the features, possibilities and advantages of distance learning in the conditions of the teachers' independent choice of such a training format, but there is an obvious lack of research concerning the problem of forced learning in distance mode. Self-isolation, in which the population found itself in COVID-19 pandemic, was forced and, accordingly, students were transferred to distance learning without their will and desire. The current situation provoked various psychological problems that need to be studied, comprehended and taken into account when organizing students education.

\section{Results}

In order to study the attitude of university students to distance learning in the context of the COVID-19 pandemic, we conducted a study with students of the Rostov-on-Don State Technical University, with a total sample of 97 people. The study involved bachelors $(75 \%)$ and masters $(25 \%)$ of the humanities and natural sciences. The age range of the respondents is from 18 to 38 years old, of which $44.3 \%$ are 20 years old. More than $80 \%$ of the respondents were female students and $19.6 \%$ were male students.

The research was carried out using the following methods: observation, interview, psychological diagnostics. The following methods were used: authors' questionnaire, 
McLane's uncertainty tolerance scale. The diagnostic results were processed using the methods of mathematical statistics.

The analysis of the results of the questionnaire on the subject of studying the attitude of students to distance learning and the use of Internet environment showed the following. When studying the target orientation of using the Internet by students, it can be noted that with the entry into distance education, the online behavior strategies of students in the Internet has not changed much. Using Internet for entertainment and communication with friends is still dominant. With the introduction of the distance learning format, students were unable to quickly rebuild and more actively use Internet resources for learning. Despite the fact that learning has mostly become online, only $10.3 \%$ use Internet for teaching purposes.

As seen on Figure 1, most of the time respondents spend on communication in social networks $(35.1 \%)$, reading and watching news is preferred by $22 \%$ of respondents, more than $20 \%$ are looking for information for their needs and $14.4 \%$ of students are actively studying online, participating in marathons, webinars.

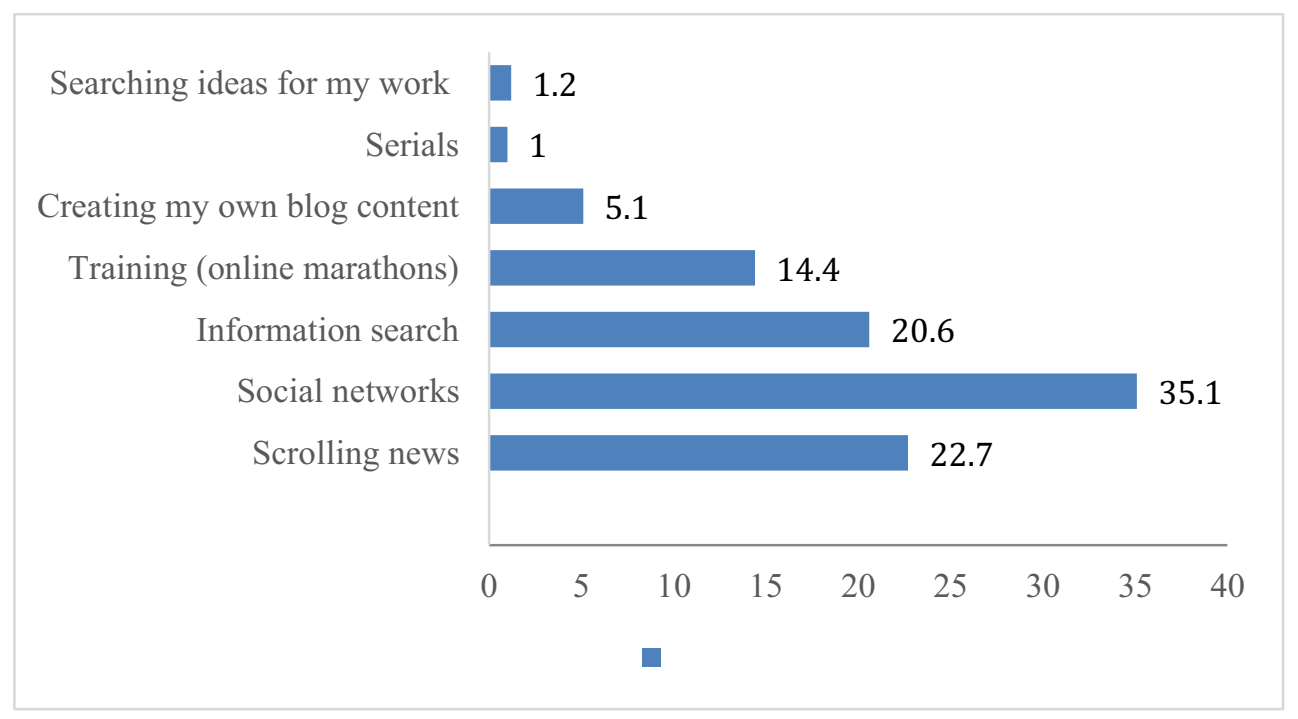

Fig.1 Students' answers to the question "What do you spend the most time on the Internet on?"

The conducted research showed that only $10 \%$ of the students use the Internet for teaching purposes. About $62 \%$ of students noted that they use the Internet for teaching purposes when necessary, and $35 \%$ indicated that they turn to Internet resources on a daily basis when teaching.

The results obtained may indicate, on the one hand, the stereotyped attitudes and strategies of student behavior, and, on the other hand, the insufficient motivation of students by teachers on active using of Internet resources for learning, focusing them on independence and self-organization of distance learning.

Thus, we can conclude that only a third of students actively use the Internet for teaching, the rest use it fragmentarily. The inclusion of students in the distance learning format requires the formation of internal motivation for learning, an increase in personal initiative and activity, and the manifestation of independence.

When studying the evaluative attitude of students to distance learning during the COVID-19 pandemic, it was found that more than half of the respondents $(51.5 \%)$ express a negative attitude towards distance learning, arguing by the fact that "it is an ineffective teaching method", that many students "lacked live communication with the teacher", "there 
were many homework assignments, which were redundant and which were often formal and not meaningful enough". Students clearly indicated that they lacked feedback, as evidenced also in interviews with teachers.

Slightly more than $40 \%$ of the respondents expressed a positive attitude towards distance format of education, expressing more neutral assessments ("there was no need to go away," "it was convenient," etc.).

Answering to the question "If you were given a choice, what form of study would you choose for yourself?" the majority of students (79.4\%) preferred full-time education. One of the main arguments in favor of this teaching format was direct contact with the teacher. About 3\% of students favored mixed learning, that is, a combination of full-time and distance learning. The rest of the respondents have chosen distance learning, interaction with the teacher online. The obtained results may indicate that most of the students are not ready for distance learning. The majority of students (68\%) noted as the main advantage of distance learning that with this format of education "there is no need to go anywhere, which saves time and material resources". Students focused on distance learning noted that with this learning format, "mental activity is activated, and involvement in the learning process increases".

When studying the advantages of distance learning (Fig.2), the first place came out convenience and comfort ("I don't have to leave the house", "I master the educational material better"), the predominant motivation is based on personal interest and convenience. Also, the following aspects were noted as positive: health preservation, compliance with human biorhythms.

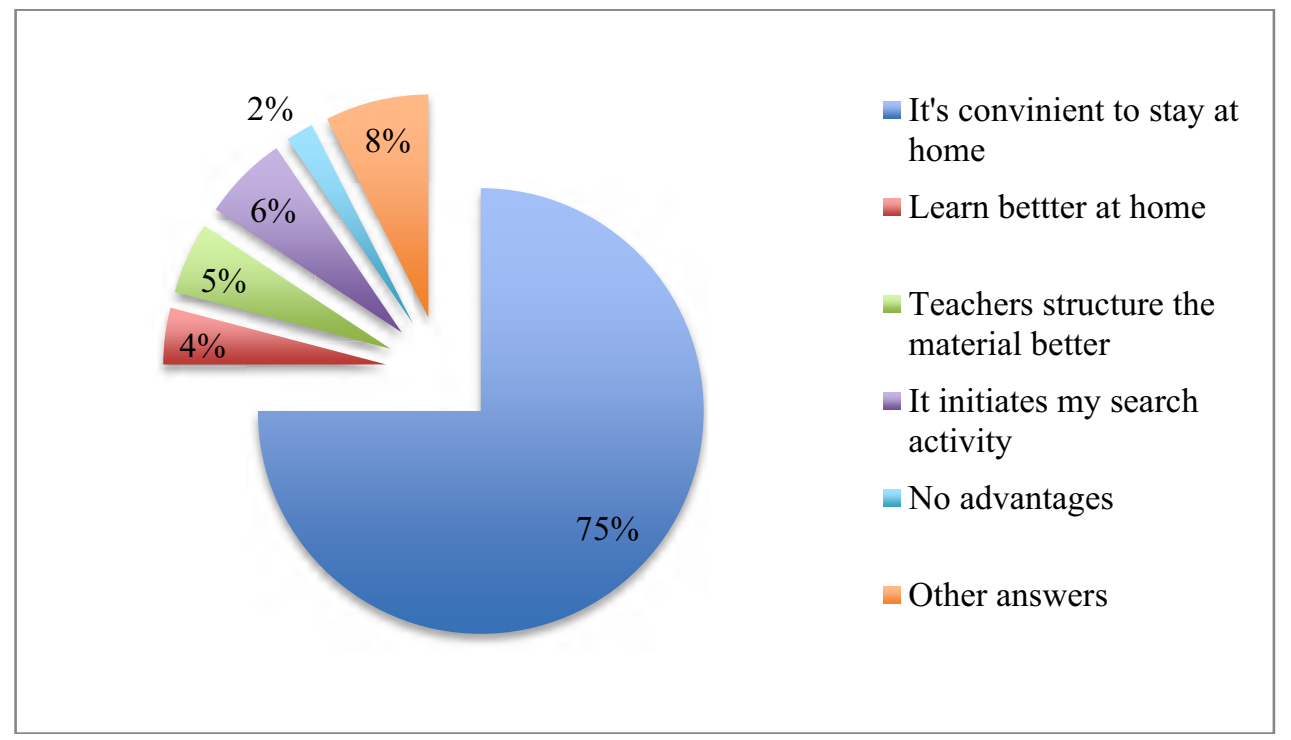

Fig. 2. The main advantages of distance learning in the students' opinion

As the main disadvantages of distance learning the students named the following: lack of direct contact with the teacher, reduced learning efficiency (27.8\%), high distraction from the learning process in a home environment (Fig.3). 


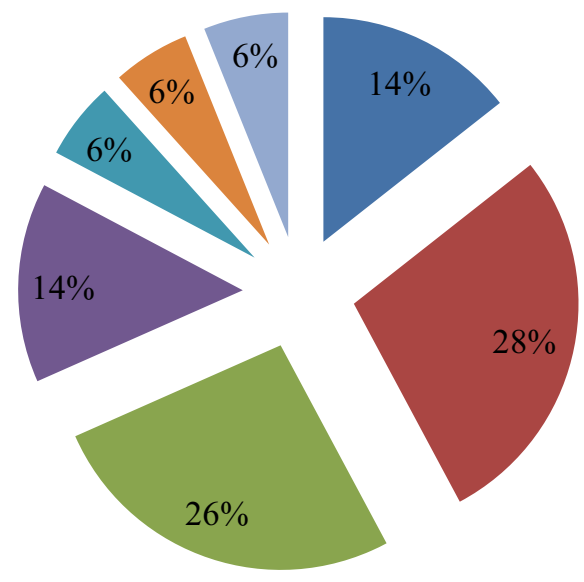

Lack of contact with teacher

- Low effectiveness

Lots of distractions at home

Lack of attention from teacher

- Too busy at home

Losing learning motivation

Fig. 3. The main disadvantages of distance learning in the students' opinion

Analysis of students' answers about the conditions that can increase the effectiveness of distance learning showed that, it is important to change the teaching methodology $(20.6 \%)$, about $40 \%$ of respondents noted that it is necessary to use more schemes, virtual games, trainings. A change in the ratio of lectures and practical classes was indicated by $16.5 \%$ of respondents, and students also noted that it would be desirable to use workbooks with assignments.

Thus, the obtained results indicate that students need psychological, pedagogical and methodological support from a teacher. The effectiveness of distance learning depends, according to students, on the availability of developed educational and methodological materials for the studied disciplines and a roadmap for learning through the labyrinths of scientific knowledge.

Taking into account the fact that the development of new learning technologies depends on the ability to rebuild and respond quickly to changes, we analyzed the indicators of the severity of tolerance to uncertainty. The level of tolerance to uncertainty among the studied group of students is within low and below average values. The focus on convenience and unwillingness to leave the comfort zone distinguishes this sample of student youth.

Revealing the attitude of students to distance learning, made it possible to identify a low level of educational activity of students in conditions of distance learning, an orientation towards convenience and comfort, and direct interaction with teachers.

The study of the correlation between the evaluative attitude of students to distance learning and tolerance to uncertainty showed no statistically significant relationships between the studied indicators, as evidenced by the Spearman correlation coefficient $(r>$ $0.362, p>0.05)$. These results can be explained by the unwillingness to accept the teaching format, which is imposed on the students from above, the inability to quickly rebuild and accept reality as it is.

\section{Conclusion}


Thus, we can draw main conclusions of the conducted empirical study:

- the directive transition to a distance learning format at a university during the coronavirus pandemic provoked students' psychological resistance to accepting distance learning as the main form of education (about $80 \%$ of students called for full-time education);

- negative attitude to distance learning of students $(51.5 \%)$, in our opinion, is determined, on the one hand, by the psychological unwillingness of students to study online, and on the other hand, by technical problems and the unwillingness of the educational system to work remotely;

- a positive attitude towards distance learning was expressed by $41.2 \%$ of respondents, they to a greater extent demonstrated external agreement, in some way conformism, as evidenced by the results of readiness to learn online, expressed by only $17.7 \%$ of students;

- the majority of university students have not formed an internal motivation to study remotely, self-discipline has not been formed;

- distance education makes increased demands on the independent work of students and the ability of their students to self-organize, which should be paid attention to by university teachers when preparing educational and methodological support;

- the experience of online education at the university has revealed many contradictions that need to be identified, studied and promptly responded.

Thus, it can be concluded that the effectiveness and quality of higher education in conditions of increasing uncertainty depends on the willingness of the teaching community to change teaching methods and techniques that correspond to the format of distance learning, on the quality of teaching materials used, guidance, teachers' skill, on the ability of teachers to pre-adaptation, as well as from students' motivation to distance learning and readiness for regular independent work, from their self-discipline and self-organization. Changes in the nature of communications in the field of higher education require further development and appropriate educational and methodological support.

\section{Discussion}

Our study is in line with the results of T. Muthuprasad, S. Aiswarya, K. S. Aditya and K. Jha Girish [14], who have studied student's perception and preference towards the online learning in India during COVID-19 pandemic and advantages/disadvantages of distance learning for students. Results of the study indicate that flexible schedule and convenience was ranked as the major benefits of the online learnings. Among other advantages students ranked more comfortable environment, enhancing the technical skills, more interaction and greater ability to concentrate and self-discipline and responsibility. The main constraints of distance learning in India are connected with technical limits (data speed, data limit, lack of connectivity) [14]. But psychological and pedagogical disadvantages of distance learning for indian students are in good agreement with our results. Students in both studies listed "no face to face interaction with teacher" and "intense requirement for self-discipline" as the most serious limitations od distance learning.

Our results contrast with the conclusions of the similar study in UAE universities. It was shown that $55 \%$ of the students liked distance learning. The analysis revealed $26 \%$ would like to study $100 \%$ online, while majority of students $49 \%$ are in favor of studying through blended learning system, which is combination of online and in-class[15] Perhaps, these differences can be explained in the context of peculiarities of national education systems and different expectations of students in different countries.

\section{Limitations}


Our work has clearly some limitations. The present study has only investigated the connection between evaluative attitude of students to distance learning and tolerance to uncertainty. But there is still a number of psychological characteristics of a person that can be connected with the level of emotional acceptance of distance learning format: state and trait anxiety, hardiness, self-control, stress resistance, learning motivation, etc.

The article was supported by the Russian Foundation for Basic Research RFBR (Project No. 1829-22004 (2018) «Psychological and genetic studies of users' behavior predictors that determine the perception of Internet content of various informational orientation»).

\section{References}

1. M. Freeston, A. Tiplady, L. Mawn, G. Bottesi, S. Thwaites, The Cognitive Behaviour Therapist, 13(31), 1-15 (2020) doi:10.1017/S1754470X2000029X

2. L. Saraite Sariene, C. Caba Pérez, A. M. López Hernández, PLoS ONE, 15(9), (2020) doi: 10.1371/journal.pone.0238801

3. N. Robinson-Garcia, R. Costas, T. N. van Leeuwen, PeerJ 8:e9410 (2020) doi: 10.7717/peerj. 9410

4. J-C. Burgelman, C. Pascu, K.Szkuta, R. Von Schomberg, A. Karalopoulos, K. Repanas, M. Schouppe, Front. Big Data, 2, 43 (2019) doi:10.3389/fdata.2019.00043

5. F. J. de O. Araújo, L. S.A. de Lima, P. I. M. Cidade, C. B. Nobre, M. L. R. Neto, Psychiatry Research, 288 (2020) doi: 10.1016/j.psychres.2020.112977

6. D. J. Bell, M. M. Self, C. Davis III, F. Conway, J. J. Washburn, F. Crepeau-Hobson., American Psychologist (2020). doi: 10.1037/amp0000673

7. A. Thatcher, M. Zhang, H. Todoroski, A. Chau, J. Wang, G. Liang, Risk Financial Manag. 13, 188 (2020) doi: 10.3390/jrfm13090188

8. D. Taylor, J. Grant, H. Hamdy, L. Grant, H. Marei, M. Venkatramana, MedEdPublish, 9(1), 1-12 (2020)

9. A. M. Al-Hosan, N. M. AlRajeh Boshra, A. Arnout, J Public Affairs, e2332 (2020)

10. I. V. Abakumova, I. A. Bakaeva, K. Y. Kolesina, IJCRSEE, 4, 1-7 (2016)

11. B. Rockenbach, S. Almagno, International information and library review, 32(3/4), 453 - 461 (2000)

12. I. V. Abakumova, I. A. Bakaeva, A. V. Grishina, E. V. Dyakova, IJCRSEE), 7(1), 8594 (2019) doi: 10.5937/ijcrsee1901085A

13. E. V. Brodovskaya, A. Y. Dombrovskaya, R. V. Pyrma, A. V. Sinyakov, A. A. Azarov, Monitoring of Public Opinion: Economic and Social Changes, 1, 228-251 (2019). doi: 10.14515/monitoring.2019.1.11

14. T. Muthuprasad, S. Aiswarya, K.S. Aditya, K. Jha. Girish. Social Sciences \& Humanities Open, 38 (2020) doi: 10.2139/ssrn.3596056

15. N. A. S. Almuraqab., SSRN Electronic journal, 3620824 (2020) 